\title{
DISLOCATION OF THE CARPAL SCAPHOID.
}

BY LEONARD W. ELY, M.D.,

OF NEW YORK.

Disiocatron of the scaphoid bone of the wrist, without fracture, is a very rare injury. In his book on fractures and dislocations, Stiuson gives only two anthentieated cases. Fracture of the seaphoicl, with dislocation, is also rare. Accorrling to the same writer, there a re only five cases on record.*

The history of this ease is as follows: On the ist of February, 1903, an antomobile in which the patient, a man of twentyfive, was ridling, overturned, and, as far as could be learned, some part of it fell on his right wrist. The lesion was diagnosed as crushing of the tendons of the wrist, and hot applications were prescriberl. These were continued for about twenty-four hours. When seen next morning for the first time, the wrist was swollen and infiltrated, ankl presented on its nexor aspeet a number of abrasious, showing the nature of the violence-that is, direct. Motion or pressure caused pain. The case appenred to be a Colles's fracture, and the patient was told that he must take an anasthetic and have it recluced. The operation was clone that afternoon.

Uncler ether, crepitus could be distinctly perceived in the wrist, though its origin conld not be exactly ascertained. By manipulation, the scaplioid could easily be dislocated on the dorsum of the wrist, and by pressure conld be replacel. On this symptom the diagnosis was made. The skiagram taken at a later date slows a slight tipping forward of the scaphoid, and a chipping off of the styloid process of the ulna; but we slatl remain in doulst whether the lesion was a simple dislocation of the scaphoid, or whether it was accompanied by a fracture of this or of one of the neigliboring bones. The skingran slowel no sucl fracture, lut the crepitus seemel to come from a point very near the scaphoid. The dislocation, however, was numistakable.

* AxNsis of SURgeny, rol. xxxy, p. 257. 
The treatment was by anterior and posterior molded plasterof-Paris splints, the posterior splint reaching to the end phalanges, the anterior to the metacarpophalangeal joints. At the end of one week the anterior splint was removed, and at the end of about three weeks the posterior splint was taken off, and adhesive tape was applied to the forearm and hand. This was left on for about two weeks, permitting some motion, but affording a certain amount of support.

The patient recovered with a good clegree of motion in all directions.

In Stimson's two cases of fracture, he made his diagnosis sure by cutting down and excising the misplaced fragments. The displacement in our case was not sufficient to warrant this, and the wounds on the anterior surface, being mere abrasions, did not ncessitate a cutting operation.

The injury is a rare one, but our experience leads us to think that it may occur without recognition. If we had not used an anxesthetic, the nature of the injury wonld probably have escaped us, for only when the muscles were completely relaxed by the ether could the scaphoid be moved abont. Perhaps Colles's fracture bears some blame it does not deserve, and crushing of the tendons at the wrist might be thought to cause great disability and deformity.

[T The writer acknowiedges his indebtedness for assistance to $\mathrm{Dr}$. William C. Clarke, who was the first to recognize the trie nature of the injury.] 


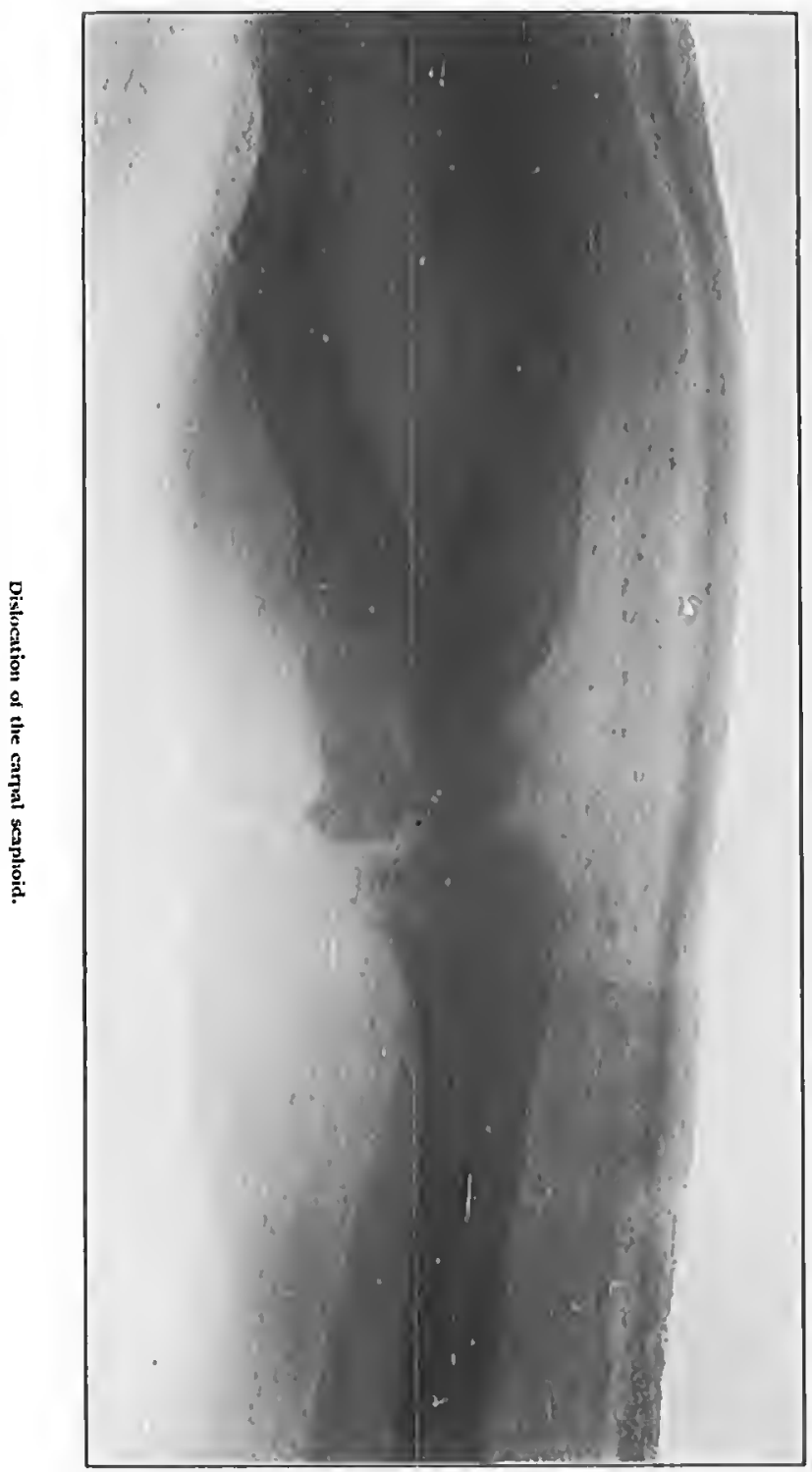


